\title{
Multimedia Learning Introduction to Animal Development in Primary School Students Using Adobe Flash Cs 3 (Multimedia Pembelajaran Pengenalan Perkembangan Hewan Pada Siswa Sekolah Dasar Menggunakan Adobe Flash Cs 3)
}

\author{
Irzal Arief Wisky ${ }^{1}$, Riki Iskandar ${ }^{2}$, Dinul Akhiyar ${ }^{3}$ \\ 1 Sistem Informasi, Universitas Putra Indonesia "YPTK" Padang \\ 2 Desain Komunikasi Visual, Universitas Putra Indonesia "YPTK" Padang \\ E-mail : irzal_ariefwisky@upiyptk.ac.id
}

\begin{abstract}
Abstrak
Media merupakan salah satu faktor yang turut menentukan keberhasilan pengajaran karena ia membantu siswa dan guru dalam menyampaikan materi pelajaran sehubung dengan tujuan pengajaran. Dalam kondisi ini penggunaan media pembelajaran dalam bentuk multimedia dapat meningkatkan efesiensi proses dan kualitas hasil belajar mengajar. pemakaian media dalam proses belajar mengajar dapat membangkitkan keinginan dan minat yang baru, membangkitkan motivasi dan rangsangan belajar. Dalam menghadapi siswa yang dapat dikatakan belum mampu memotivasi dirinya sendiri ini, menjadi sebuah tantangan bagi seorang guru. Sehingga dengan penerapan aplikasi multimedia dapat membantu siswa dalam belajar, melatih dan mengarahkan peserta didik pada sekolah dasar dalam pengenalan perkembangan hewan.
\end{abstract}

Kata kunci: Media,Aplikasi, Multimedia.

The media is one of the factors that also determines the success of teaching because it helps students and teachers deliver the subject matter in connection with the teaching objectives. In this condition the use of instructional media in the form of multimedia can improve the efficiency of the process and the quality of teaching and learning outcomes. the use of media in the teaching and learning process can arouse new desires and interests, generate motivation and stimuli for learning. In dealing with students who can be said to not be able to motivate themselves, this becomes a challenge for a teacher. So that the application of multimedia applications can help students in learning, training and directing students in primary schools in the introduction of animal development.

Keywords: Media, Application, Multimedia. 


\section{Pendahuluan}

Salah satu hal yang dapat dilakukan oleh guru adalah penggunaan media pembelajaran. Penggunaan media pembelajaran ini juga dapat dikatakan sebagai salah satu strategi yang dilakukan guru dalam rangka memaksimalkan penyampaian materi kepada siswa. Dalam memilih media pembelajaran, guru juga harus memperhatikan berbagai hal. Media pembelajaran yang digunakan harus komunikatif serta mampu menarik perhatian siswa. Media yang digunakan juga harus disesuaikan dengan materi serta tujuan pembelajaran. Pada tahap pendidikan anak usia MI/SD, siswa akan cenderung lebih tertarik dengan permainan yang mudah dimainkan dan di dalamnya terdapat warna-warna cerah serta gambar animasi yang menarik perhatian. Saat ini kebanyakan pembelajaran di sekolah masih digunakan metode ceramah, fasilitas media buku panduan dan Lembar Kerja Siswa (LKS). Untuk menunjang peningkatan kualitas pembelajaran sangat dipengaruhi oleh media pembelajaran yang digunakan. Semakin berkualitas media pembelajaran yang digunakan maka semakin berkualitas pula proses pembelajaran tersebut. Salah satu media pembelajaran yang dapat menghadirkan suasana yang menyenangkan dan interaktif bagi siswa adalah media berbasis komputer dengan menggunakan software flash dengan Adobe Flash CS3 Professional.

\section{Landasan Teori}

\subsection{Pengertian Sistem Informasi}

Sistem informasi adalah cara-cara yang diorganisasi untuk mengumpulkan, memasukkan, dan mengolah serta menyimpan data, dan cara-cara yang diorganisasi untuk menyimpan, mengelola, mengendalikan, dan melaporkan informasi sedemikian rupa sehingga sebuah organisasi dapat mencapai tujuan yang telah ditetapkan ${ }^{[1]}$.

\subsection{Kualitas Informasi}

Kualitas suatu informasi (Quality of intabilation) tergantung pada tiga hal, yaitu Infromasi harus akurat (Accurate), tepat pada waktunya (Timely Basis) dan relevan (Relevance)

a. Akurat

Informasi dikatakan akurat apabila informasi tersebut bebas dari kesalahankesalahan dan tidak bias atau menyesatkan. Akurat juga berarti infromasi harus jelas mencerminkan maksudnya.

b. Tapat Waktu

Harus tepat waktu maksudnya informasi yang datang pada penerima tidak boleh terlambat. Informasi yang sudah usang tidak akan mempunyai nilai tinggi lagi.

c. Relevan

Relevan berarti informasi tersebut mempunyai manfaat untuk pemakainya. Relevan informasi untuk tiap-tiap orang satu dengan yang lainya berbeda.

\subsection{Graphical User Interface (GUI)}

Graphical User Interface (GUI) adalah Desain user interface termasuk dalam bidang ilmu interaksi antara manusia dan komputer (HCI: human computer interaction). Interaksi antara manusia dan komputer adalah ilmu tentang perancang desain untuk membuat manusia dan komputer bekerja sesuai tujuan yang ingin dicapai secara efektif ${ }^{[2]}$.

\subsection{Desain Grafis}

Desain grafis menentukan keindahan tampilan suatu program. Keindahan di pengaruhi oleh kombinasi warna yang digunakan, pengaturan tata letak serta bentuk ${ }^{[3]}$. Hal-hal yang perlu diperhatikan dalam membuat desain yang sesuai yaitu :

a. Pemilihan Warna

Warna berhubungan dengan indera pengelihatan. Pemilihan warna merah pada tombol button mempunyai tujuan untuk memperjelas tampilan tombol button, maka digunakan warna cerah. Jurnal KomtekInfo Vol : 7 No : 1//2020 
Penggunaan warna yang sesuai mempengaruhi keindahan desain. Dalam desain, warna dianggap sebagai cahaya.

b. Tipografi

Tipografi merupakan seni penggunan huruf. Penggunaan huruf menentukan kemudahan pembaca teks. Apabila banyak teks yang ditulis, maka disarankan menggunakan huruf yang standar misalnya times new roman atau verdana.

c. Bentuk

Desain memiliki 3 bentuk dasar, yaitu lingkaran, kotak/persegi dan segitiga. Penggabungan bentuk dasar tersebut dapat menghasilkan bentuk lain yang bervariasi.

d. Tata Letak

Tata letak dapat memberikan kesan cantik dan seimbang. Pengaturan tata letak yang baik memudahkan pengguna untuk membaca informasi yang disampaikan.

\subsection{Sistem Multimedia}

sistem multimedia adalah suatu sistem yang dapat mendukung secara integrasi penyimpanan, transmisi dan representasi sejumlah media discrate (digital) berupa text, grafik, citra, audio, dan video melalui komputer ${ }^{[4]}$.

sistem multimedia adalah beberapa sistem yang mendukung lebih dari satu macam sistem ${ }^{[5]}$.

\subsection{Elemen-Elemen Multimedia}

a. Animasi

Animasi secara harfiah berati menjadikan hidup atau bergerak. Animasi juga biasa berarti membuat objek bergerak dan hidup. Menganimasikan memiliki makna menggerakkan objek agar menjadi hidup.

b. Gambar

Gambar (Image) atau grafik merupakan salah satu bentuk penyajian data. Pada dasarnya format gambar ada dua yaitu Bitmap dan Vektor. Gambar atau grafik merupakan bagian terpenting dalam dunia multimedia. Sebab sebuah gambar dapat menggambarkan ribuan kata-kata. Pada dasarnya sebuah pengolahan gambar dapat dipresentasikan ke dalam 2 (dua) tipe yaitu Pixel dan Vektor.

c. Suara

Sebelum munculnya teknologi "Interface Sound Card", para pemakai PC hanya terpuaskan dengan menengarkan suara melalui speaker komputer. Tahun 1989 “ Interface Sound Card (Sound Card)"sudah mulai digunakan oleh pemakai PC. Sound Card mempunyai peranan yang cukup penting bila ditinjau dari visi utama multimedia.

d. Text

Teks dalam multimedia sangat diperlukan untuk penyajian informasinya ataupun untuk memperjelas informasinya. Sekalipun sebuah gambar mungkin menggambarkan ribuan kata-kata, tetapi gambar tersebut tanpa dilengkapi dengan teks ataupun beberapa kutipan deskriptif maka akan sulit diterima dan pengenalan.

e. Video

Video merupakan susunan gambar yang digerakan. Video juga merupakan salah satu media audio visual yang digunakan sebagai media komunikasi. Video dapat digunakan untuk menjelaskan pesan, memberi pendidikan, dan juga bisa memberi hiburan.

\subsection{Media Pembelajaran}

Media pembelajaran adalah alat yang berfungsi untuk menyampaikan pesan pembelajaran. Media pembelajaran juga merupakan cara untuk berkomunikasi dan memotivasi pengguna agar lebih efektif. Oleh karena itu sangat diperlukan media pembelajaran guna membantu proses dalam belajar bagi pengguna $^{[6]}$.

\section{Analisa dan Perancangan}




\subsection{Perancangan Sistem Dengan Menggunakan UML}

Unfied Modelling Language (UML) adalah sebuah "bahasa" yang telah menjadi standar dalam industri untuk visualisasi, merancang dan mendokumentasikan sistem perangkat lunak, alat bantu berupa Unified Modelling Language (UML) agar mempermudah memindahkan konsep sistem yang dirancang ke dalam bentuk program, dimana perancangannya digambarkan dalam bentuk diagram-diagram berikut :

a. Use Case Diagram

Use case diagram menjelaskan manfaat dari aplikasi jika dilihat dari sudut pandang orang yang berada diluar sistem (aktor). Diagram ini menunjukkan fungsionalitas suatu sistem atau kelas dan bagaimana sistem berinteraksi dengan dunia luar. Use-case diagram dapat digunakan selama proses analisa untuk menangkap requirements atau permintaan terhadap sistem dan untuk memahami bagaimana sistem tersebut harus bekerja, seperti gambar 3.1 :

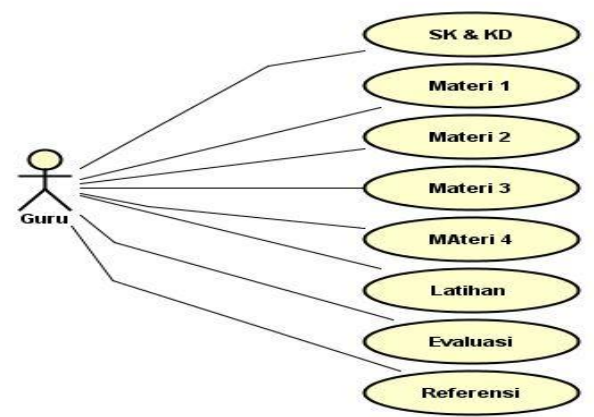

Gambar 3.1 Use Case Diagram

b. Activity Diagram

Activity Diagram menggambarkan aktifitas-aktifitas yang dapat dilakukan oleh user didalam Media Pembelajaran. Dapat dilihat aktifitas dari user dapat mengakses berbagai konten seperti melihat menu Petunjuk, Materi, Evaluasi, dan menu Tentang Pengembang, seperti gambar 3.2 :

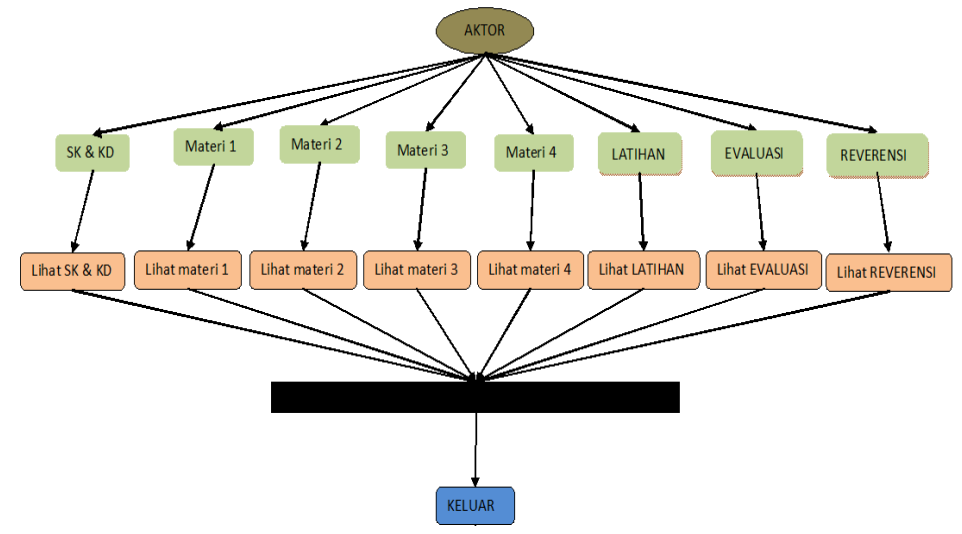

Gambar 3.2 Activity Diagram

\section{Implementasi sistem}

\subsection{Implementasi sistem}

Implementasi sistem adalah sistem yang siap pakai untuk diterapkan pada sekolah dasar. Sebelum diimplementasikan secara langsung pada suatu sekolah, perlu dilakukan pengujian terlebih dahulu.

\subsection{Pengujian Sistem}

Pada pengujian sistem ini akan menampilkan sistem dan cara kerja sistem. Pada saat program dijalankan.

1. Menu Utama.

Adapun bentuk tampilan menu utama pada media pembelajaran menggunakan adobe flash cs3, 
seperti gambar 4.1:

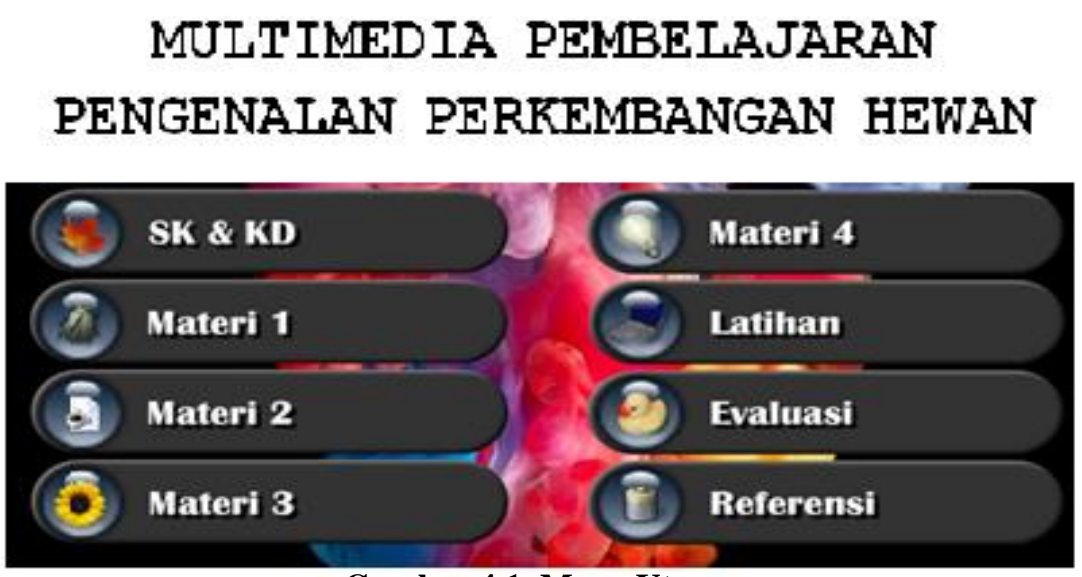

Gambar 4.1 Menu Utama

2. Menu Materi 1

Adapun bentuk tampilan menu pada media pembelajaran menggunakan adobe flash cs3, seperti gambar 4.2:
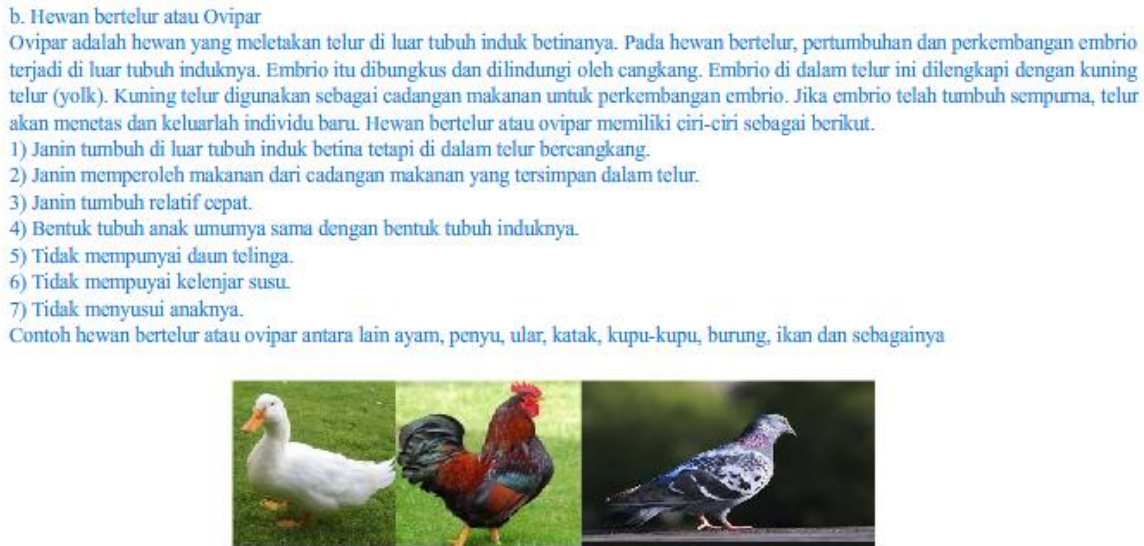

c. Hewan bertelur dan melahirkan atau Ovovivipar

Kadal sebenarnya merupakan hewan bertelur, tetapi telurnya menetas di dalam tubuh induk betina kemudian anaknya keluar dari tubuh induk betina. Hewan yang demikian disebut hewan bertelur-melahirkan atau ovovivipar. Pada hewan tersebut, setelah terjadi pembuahan, telur terus berkembang di dalam tubuh induk. Makanan yang dibutuhkan embrio tidak berasal dari induk. Akan tetapi, makanan berasal dari cadangan makanan yang terdapat di dalam telur. Setelah tiba waktunya dilahirkan, anaknya akan keluar dari tubuh induknya.

Contoh hewan ovovivipar antara lain kadal, paus, ikan pari, beberapa jenis ular dan ikan hiu.

\section{Gambar 4.2 Menu Materi 1}

3. Menu Latihan

Adapun bentuk tampilan menu pada media pembelajaran menggunakan adobe flash cs3, seperti gambar 4.3: 


\section{LATIHAN}

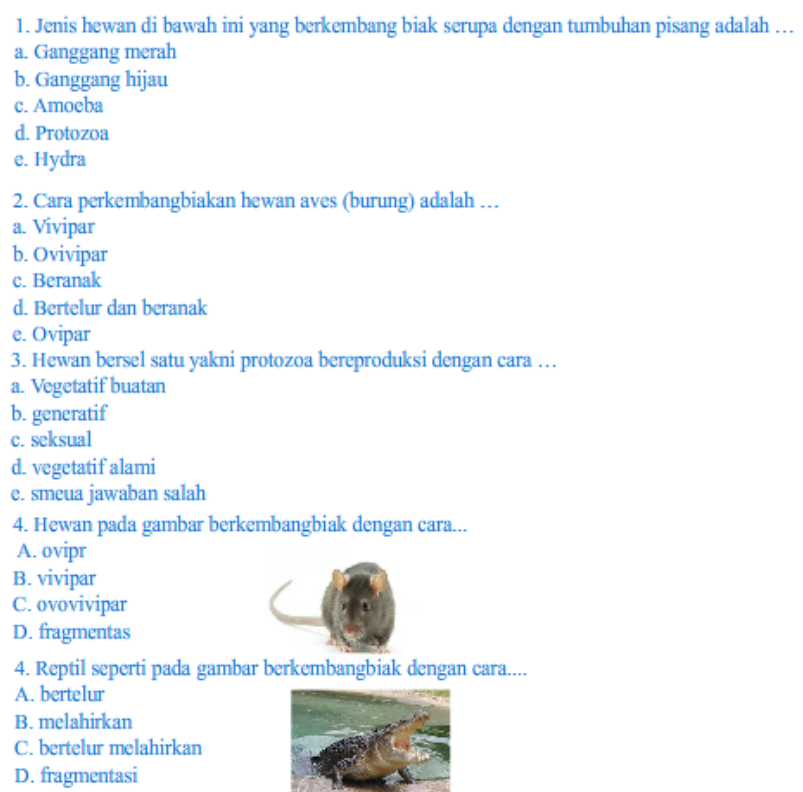

Gambar 4.3 Menu Latihan

\section{Penutup}

\subsection{Kesimpulan}

Dari deskripsi tentang multimedia pembelajaran perkembangan hewan pada sekolah dasar, sebagaimana telah dikemukakan pada bab-bab sebelumnya dan kemudian dilanjutkan dengan pembahasan masalah, maka dapat ditarik suatu kesimpulan sebagai berikut :

1. Perancangan sistem multimedia pembelajaran yang dapat memudahkan siswa dalam mengetahui perkembangan hewan.

2. Sistem multimedia pembelajarandapat membantu siswa untuk meningkatkan kemauan belajar serta kreatifitas dalam membahas materi pembelajaran.

\subsection{Saran-Saran}

Dari kesimpulan diatas dan penelitian yang dilakukan maka dapat menemukan beberapa saran yang diharapkan dapat menjadi bahan pertimbangan lebih lanjut dalam upaya peningkatan kualitas sistem yang telah dibuat. Adapun saran-saran yang ingin disampaikan adalah :

1. Diharapkan agar sistem ini selalu dilakukan perubahan agar data nya selalu update.

2. Sistem ini dibangun dengan menggunakan adobe flash cs3, pada perkembangan selanjutnya, diharapkan aplikasi ini dibangun dengan pemrograman yang lebih baru sesuai dengan perkembangan zaman.

3. Melakukan pembaruan pada interface dan sistem nya karena seiring berjalannya waktu akan lahir lagi fitur baru yang lebih memanjakan penggunanya. 


\section{Referensi}

[1] Krismiaji, 2015, Sistem Informasi Akuntansi, UPP STIM YKPN, Yogyakarta

[2] Khairurrizqi, 2015, Perancangan Graphical User Interface "Si Jambe" Sebagai Media Pembelajaran Di Jambi, eProceeding of Art \& Design, Jambi

[3] Nugrahani, Rahina, 2015, Peran Desain Grafis Pada Label Dan Kemasan Produk Makanan UMKM, Imajinasi jurnal seni, Semarang

[4] Kusuma, Elyn (2012, 2 November), "Sistem Multimedia". Retrieved from Elynkusuma.com:http //elynkusuma.blogspot.com//2012/11/sistem-multimedia.html

[5] Sugiyono, (2010), "Metode Penelitian Kombinasi (Mixed Methods)", Bandung : Alfabeta

[6] Simamora, Ns.Roymond, M.Kep (2008), "Buku Ajaran Pendidikan Dalam Keperawatan”, Jakarta : Gramedia.

[7] Suyanto, M. 2003."Multimedia Alat Untuk Meningkatkan Alat Bersaing”. Andi, Yogyakarta. 